\title{
Fibroblast growth factor 21 analogs for treating metabolic disorders
}

\author{
Jun Zhang and Yang Li* \\ Amgen Inc., South San Francisco, CA, USA
}

Fibroblast growth factor (FGF) 21 is a member of the endocrine FGF subfamily. FGF21 expression is induced under different disease conditions, such as type 2 diabetes, obesity, chronic kidney diseases, and cardiovascular diseases, and it has a broad spectrum of functions in regulating various metabolic parameters. Many different approaches have been pursued targeting FGF21 and its receptors to develop therapeutics for treating type 2 diabetes and other aspects of metabolic conditions. In this article, we summarize some of these key approaches and highlight the potential challenges in the development of these agents.

Keywords: FGF21, FGF19, FGFR1, beta-Klotho, diabetes, obesity, therapy, antibody

\section{OPEN ACCESS}

Edited by:

Yongde Luo,

The Texas A\&M University Health Science Center, USA

Reviewed by: Carol Huang, University of Calgary, Canada Vincenzo Carlo Russo, Murdoch Childrens Research Institute, Australia

*Correspondence:

Yang Li

yangl@amgen.com

Specialty section: This article was submitted to Cellular Endocrinology, a section of the journal Frontiers in Endocrinology

Received: 04 September 2015 Accepted: 22 October 2015

Published: 05 November 2015

Citation:

Zhang J and Li Y (2015) Fibroblast growth factor 21 analogs for treating metabolic disorders.

Front. Endocrinol. 6:168. doi: 10.3389/fendo.2015.00168

\section{INTRODUCTION}

Fibroblast growth factors (FGFs) are a group of signaling proteins with a conserved core domain of about 120 amino acids. These molecules display diverse functions from embryonic development, and tissue regeneration, to maintenance of metabolic homeostasis. Aberrant FGF signaling is linked to a range of pathological conditions, from cancer to metabolic disease $(1,2)$. FGFs function through single-pass transmembrane receptor (FGFR) proteins with three extracellular immunoglobulintype domains (D1-D3) and an intracellular tyrosine kinase domain. Seven major FGFRs (FGFR1b, FGFR1c, FGFR2b, FGFR2c, FGFR3b, FGFR3c, and FGFR4) encoded by four FGFR genes mediate FGF functions. The mammalian FGF family comprises 18 members that are subdivided into six groups based on phylogenetic analysis (3). Five of the six subfamilies are paracrine molecules in that they are secreted, retained, and function in local tissues where they are produced due to high affinity interactions with heparan sulfate (HS) proteoglycans in the extracellular matrix. The exception is the FGF19 subfamily, consisting of FGF15/19, FGF21, and FGF23, which have reduced affinity for HS. Instead, they use single-pass transmembrane proteins of the Klotho family ( $\alpha$-Klotho or $\beta$-Klotho) as co-receptors to activate FGFR signaling in an endocrine fashion. FGF19 subfamily members play important roles in metabolic pathways including bile acid metabolism, energy expenditure, and glucose, lipid, vitamin $\mathrm{D}$, and phosphate homeostasis (3).

The human FGF21 is a 209 amino acid protein with a mature secreted polypeptide of 181 amino acids. FGF21 is mainly expressed in the liver, but is also upregulated in many other tissues upon various stimulations $(4,5)$. While it binds to FGFRs with very low affinity in the presence of heparin/ HS, FGF21 efficiently binds to and activates FGFR1c, FGFR2c, and FGFR3c in the presence of coreceptor $\beta$-Klotho in vitro (6-8). In vivo, $\beta$-Klotho and FGFRs are co-expressed in several tissues in which FGF21 is shown to signal, and thus are potential target tissues mediating its physiological and pharmaceutical actions.

Many studies reveal FGF21 as a multifunctional metabolic regulator and its levels are significantly increased under many pathological conditions. For example, in mice, studies from Fgf21 knockout $(\mathrm{KO})$ and transgenic mice suggest diverse actions of FGF21 on many metabolic organs 
to regulate glucose, lipid, and energy metabolisms (9-12). In humans, circulating FGF21 levels are elevated in obese subjects $(13,14)$, patients with impaired glucose tolerance (15), type 2 diabetes mellitus $(13,15,16)$, dyslipidemia (17), and nonalcoholic fatty liver disease (NAFLD) $(18,19)$. Elevated serum FGF21 levels are also seen in subjects with coronary heart disease (CHD) $(20,21)$ and in patients with carotid atherosclerosis (22). Serum FGF21 levels increase with progression of chronic kidney disease (CKD), chronic and acute renal dysfunction $(23,24)$, cold-induced thermogenesis, and brown adipose tissue (BAT) activity $(25,26)$. Altogether, these findings suggest that targeting FGF21 and its pathway components may have broad impact on various human conditions. Since the physiological and pharmacological functions of FGF21 have been extensively reviewed in Ref. (27-34), in this article, we only briefly summarize the potential connections between FGF21 and disease conditions to suggest potential areas that may benefit from FGF21 treatment. We will focus the discussion on key approaches for therapeutic development of FGF21 analogs.

\section{FGF21 SIGNALING IN METABOLIC DISEASES}

\section{Role of FGF21 in Diabetes and Obesity}

FGF21 has emerged as an important metabolic hormone involved in the regulation of glucose, lipid, and energy homeostasis. FGF21 transgenic animals show lower levels of serum insulin, glucose, triglycerides (TG), cholesterol, lower hepatic TG content, improved insulin sensitivity, resistance to diet-induced obesity, and a significantly extended lifespan compared with their wildtype counterparts (35-37). Likewise, recombinant FGF21 also demonstrates a dramatic effect in normalizing plasma glucose levels, improving insulin sensitivity, reducing plasma TG and cholesterol levels in various diabetic animal models and diabetic rhesus monkeys, exhibiting an attractive profile as a potential novel therapy for treating metabolic disorders (35, 38-42).

The ability of FGF21 to affect a major metabolic tissue function was first demonstrated on adipocytes. FGF21 increases insulinindependent glucose uptake into cultured 3T3-L1 mouse adipocytes and primary human adipocytes through the upregulation of glucose transporter 1 (GLUT1) expression (35). Subsequent studies reveal that FGF21 regulates adipocyte lipolysis $(5,43,44)$ and increases adiponectin expression and secretion $(45,46)$. The central role of fat tissue to FGF21 function was demonstrated in a lipoatrophic mouse model (mice severely depleted of adipose tissue) (47), where recombinant FGF21 treatment cannot correct the hyperglycemia and insulin resistance in these mice in contrast to wild-type animals. Reconstitution of adipose mass by transplanting white adipose tissue (WAT) from wild-type mice to lipoatrophic mice restores FGF21 responsiveness (48). Fatspecific KO of FGF21 receptors, $\beta$-Klotho and FGFR1, abolishes FGF21-induced bodyweight reduction and improvement in serum glucose and lipid parameters $(36,49,50)$, further suggesting an important role for fat tissue in FGF21 biology.

FGF21 stimulates uncoupling protein 1 (UCP1) gene expression in both BAT and WAT and dramatically increases the appearance of "brown-like" adipocytes in subcutaneous WAT (51-53). These effects may contribute to the thermogenic activities of FGF21 and to promote weight loss under high fat conditions. In mice, FGF21 expression is upregulated in response to cold exposure and $\beta$-adrenergic stimulation $(11,54,55)$. In rats, cold exposure induces a marked release of FGF21 from BAT, suggesting an endocrine role of BAT as a source of FGF21 that may be relevant in thermogenic activation (55). In humans, changes in serum FGF21 concentrations correlate positively with cold-induced thermogenesis (25), and circulating FGF21 levels correlate with BAT activity during acute cold exposure in male subjects, indicating a possible role for FGF21 in maintaining normothermia (26). Although two recent studies utilizing Ucp1 KO mice challenge the importance of WAT browning in FGF21 mediated pharmacology, the importance of these effects in humans remain to be resolved $(56,57)$.

Brain is another direct target of FGF21 action. FGF21 crosses the blood-brain barrier, and FGFRs and $\beta$-Klotho are expressed in certain areas of the brain [reviewed in Ref. (34)]. Central administration of FGF21 increases energy expenditure, insulin sensitivity, and hepatic gluconeogenesis, while knocking out $\beta$-Klotho centrally abolishes the effects of FGF21 on metabolism, circadian behavior, growth, and female reproduction (34), demonstrating an essential role of the nervous system in the actions of FGF21. Future studies are needed to understand the interplay between brain and adipose tissue in FGF21 responses.

\section{Role of FGF21 in Liver, Chronic Kidney, and Cardiovascular Diseases}

Liver is a major site for both production and action of FGF21. The hepatic expression and plasma levels of FGF21 in mice are markedly elevated upon fasting, or consumption of a ketogenic diet, and are suppressed by re-feeding $(5,58,59)$. It is induced directly by peroxisome proliferator-activated receptor (PPAR) $\alpha$ activation and mediates hepatic ketogenesis, and increases fatty acid oxidation, glucose flux, gluconeogenesis, and improves insulin sensitivity $(5,39,40,58,59)$. Overexpression of FGF21 or recombinant FGF21 injection exhibit increased ketogenesis in liver (5) and Fgf21 KO mice show impaired fatty acid oxidation in liver and develop hepatosteatosis (11). Elevated FGF21 levels have been associated with multiple liver diseases, including alcoholic liver diseases (ALD), NAFLDs, non-alcoholic steatohepatitis (NASH), hepatocellular carcinoma (HCC), and hepatitis, although the role of FGF21 in the progression of these diseases has not been defined (60).

Understanding the direct function of FGF21 on liver is complicated since most studies have focused on NAFLD in the context of obesity and pharmacologic doses of FGF21 induce rapid weight loss, making it difficult to identify the primary effects of FGF21 on liver metabolism. To bypass weight loss-associated benefits, a lean model of fatty liver disease was induced by consumption of a methionine- and choline-deficient (MCD) diet (61). This model recapitulates most pathologic processes observed in fatty liver disease, with progression to NASH and development of severe inflammation and fibrosis, without weight gain or insulin resistance. Mice fed with the MCD diet have more than 50-fold 
increased hepatic levels of FGF21 messenger RNA and 16-fold increased serum FGF21 levels. In Fgf21 KO mice, MCD diet induces more severe steatosis, fibrosis, inflammation, and peroxidative damage. These animals show reduced hepatic fatty acid activation and $\beta$-oxidation, resulting in increased levels of free fatty acid. Continuous subcutaneous infusion of recombinant FGF21 for 4 weeks in Fgf21 KO animals reverse steatosis and peroxidative damage, suggesting a direct and perhaps adipose independent role of FGF21 in liver fatty acid activation and oxidation (61).

Kidney is another tissue affected by FGF21 function. Serum FGF21 levels increase with the progression of CKD, and with chronic and acute renal dysfunction $(23,24)$. In patients with diabetic nephropathy, FGF21 levels are also independently associated with urinary albumin excretion (62), although studies on direct renal effects of FGF21 remain limited. In a recent report, recombinant FGF21, injected daily for 12 weeks into leptin receptor $\mathrm{KO} d b / d b$ mice, markedly decreases urinary albumin excretion and mesangial expansion and suppresses the synthesis of profibrotic molecules (63). Furthermore, FGF21 administration decreases cholesterol and triglyceride accumulation in the diabetic kidney, and markedly abolishes the increase of p65 protein in the proinflammatory NF- $\kappa \mathrm{B}$ pathway, all contributing factors to the progression of diabetic nephropathy (63).

Elevated serum FGF21 levels are also observed in patients with CHD $(21,64)$ and associate with both carotid atherosclerosis in women and carotid artery plaques in type 2 diabetes subjects (22, 65). Furthermore, serum FGF21 levels positively correlate with carotid and iliac lesions in patients with subclinical atherosclerosis, especially in women. High levels of FGF21 may be a compensatory reaction to offset atherosclerosis (66).

Several recent reports examined the role of FGF21 in cardiovascular diseases. FGF21 is produced by cardiomyocytes (12). Although levels of FGF21 secreted from the heart is much lower than from liver, FGF21 secreted by cardiac cells in response to cardiac stress is able to inhibit isoproterenol-induced cardiac hypertrophic damages, and protects cardiac cells against hypertrophic insults (12). The increased heart weight, signs of dilatation and cardiac dysfunction in response to isoproterenol infusion are exacerbated in Fgf21 KO animals. Treatment with recombinant FGF21 reverses cardiac hypertrophy in Fgf21 KO mice and cultured cardiomyocytes. This paracrine action of FGF21 on cardiomyocytes prevents cardiac hypertrophy by activating MAPK signaling, inducing rapid phosphorylation of cAMP response element-binding protein (CREB), leading to increased expression of PGC- $1 \alpha$ and repressed NF- $\kappa B$ proinflammatory pathway (12). FGF21 treatment also induces the expression of genes from antioxidative pathways, reduces reactive oxygen species production, and protects cells against oxidative stress, improving overall heart function and prevents heart failure (67). In a mouse model with severe defective TG catabolism due to deficiencies in adipose triglyceride lipase (ATGL), a drastic increase in heart FGF21 mRNA expression is observed. In cardiac-specific overexpression of FGF21 (CM-Fgf21) animals, FGF21, secreted from cardiomyocytes, moderately affects cardiac TG homeostasis, indicating that FGF21 is induced upon cardiac ER stress and regulates cardiac as well as whole body energy homeostasis (68).
All of these findings together suggest that modulating FGF21 pathway may have broad benefits on multiple human conditions.

The elevated FGF21 levels observed under many disease conditions may indicate a state of FGF21-resistance as suggested by several studies $(64,69)$. However, alternative explanations, for example, that the FGF21 in diseased conditions represents less active form of the hormone due to modifications, are also possible. Nonetheless, the ability to respond to pharmacological doses of FGF21 despite the increased levels under disease conditions supports the notion that FGF21 treatment may be beneficial in these disease areas.

\section{THERAPEUTIC APPROCHES TARTETING FGF21 PATHWAY}

The impressive beneficial effects exhibited by FGF21 treatment in various animal models on multiple metabolic parameters prompted considerable interest in developing therapeutics from this pathway. However, the native FGF21 molecule is not suitable as a development candidate due to short plasma half-life and poor drug-like properties (32). Considerable engineering efforts are needed to bring sufficient improvements for large-scale manufacturing and further clinical development. This section highlights several key approaches explored in the search of a suitable therapeutic candidate.

\section{Engineering the Native FGF21 Molecule}

Extensive protein engineering on FGF21 itself yields significant improvements in biophysical properties in several different expressions systems. For example, the introduction of a disulfide bond at L118C-A134C in the C-terminal domain of FGF21, sitespecific mutagenesis at $\mathrm{S} 167$ to $\mathrm{A}$, and the deletion of the first four amino acids, HPIP, are found to improve the stability, and reduce the heterogeneity and proteolysis issues associated with the wildtype protein in the Pichia pastoris yeast expression system (70). A molecule, LY2405319, that combined all three changes together, is indistinguishable from native FGF21 in physiological effects both in vitro and in preclinical rodent and monkey models, but with improved biophysical properties suitable for large-scale production $(70,71)$. LY2405319 is the first FGF21 analog to enter human clinical trial, a phase I study was conducted in obese subjects with type 2 diabetes (70). Overall, the clinical data are similar to the pharmacologic effects of FGF21 in rodent and nonhuman primates, LY2405319 significantly lowers body weight, fasting insulin levels, fasting TG, total and LDL-cholesterol, and robustly increases serum adiponectin and HDL-cholesterol levels. However, only a trend toward glucose lowering is observed (70). These results are encouraging and supports that FGF21 is bioactive in humans; however, the effectiveness of FGF21 in controlling hyperglycemia would still need to be addressed in future studies.

Engineering efforts for other expression systems are also described. To efficiently produce FGF21 from Escherichia coli, Ye et al. exchanged the beta10-beta12 domain of human FGF21 with that of the mouse sequence and then fused the chimeric protein to SUMO (72). The solubility of the resulting SUMO-FGF21 
protein is improved by twofold compared with the wild-type human FGF21. The engineered FGF21 is also more potent in stimulating glucose uptake in HepG2 cells and shows improved glucose-lowering effects in diabetic $d b / d b$ mice (72).

Other alterations are also explored to improve the stability and bioactivity of FGF21. For example, the C-terminal domain of FGF21 crucial for interaction with co-receptor $\beta$-Klotho (73-75) is also sensitive to proteolysis (76). Replacement of this segment with sequences that are both resistant to proteolytic cleavage and have higher affinity for $\beta$-Klotho can achieve both of the goals of improving stability and bioactivity. In one approach, this C-terminal domain of FGF21 is replaced with that of FGF19, believed to bind to $\beta$-Klotho with higher affinity (77); while in another approach, this C-terminal domain is replaced with a stable scaffold called Avimer ${ }^{\mathrm{TM}}$ that has high affinity to co-receptor (78). The avimer fusion molecule, FGF21 (1-171)-WD22, indeed has improved properties and decreased susceptibility to modifications compared to wild-type FGF21 (78), providing a novel framework for further engineering that is not possible with the wild-type protein.

To extend FGF21 plasma half-life by reducing clearance through kidney filtration, several size-extension approaches, such as PEGylation, fusion to Fc, serum albumin, or full antibodies, are all reported to improve the pharmacokinetic properties of FGF21.

PEGylation to FGF21 can be achieved through the N-terminal residue or a specific site on the surface of the protein. N-terminal PEGylation using 20 kDa mPEG-butyraldehyde extends FGF21 plasma half-life from $\sim 35$ min to $\sim 4$ h with reduced immunogenicity (79). Internal PEGylation can be carried out by mutating specific amino acid residues for attachment to a cysteine residue (80) or to a non-natural amino acid, p-acetylphenylalanine (81), followed by conjugation reactions for PEG attachment. In these cases, the plasma half-life extension achieves $>30 \mathrm{~h}$ in rodent. In general, PEGylation at certain positions retains good FGF21 activities in vitro and in vivo (79-81). In addition, correctly placed PEG moieties also reduce the risk of inducing kidney vacuole formation (80).

Alternative to PEGylation, half-life extension via fusion to $\mathrm{Fc}$ molecules has the potential advantage of reducing manufacturing complexity and improving homogeneity of the final product. A FGF21 analog based on fusion to the Fc fragment of human IgG1 reports such improved properties (76). The final molecule, Fc-FGF21(RG), consists of the combination of several changes, these include the selection of the N-terminus of FGF21 for Fc fusion to reduce impact on receptor binding, mutation at P171 to $\mathrm{G}$ to remove a proteolytic clipping site, and substitution of L98 to $\mathrm{R}$ to reduce aggregation (76). Fc-FGF21(RG) reports a circulating half-life of $11 \mathrm{~h}$ in mice and $30 \mathrm{~h}$ in monkeys $(76,82)$. In rodent models and obese rhesus monkeys, a single injection of Fc-FGF21(RG) displays a sustained reduction in blood glucose levels, lipids, and bodyweight for 5-7 days, demonstrating a profile consistent with once-weekly dosing (83).

Fusion to scaffold monoclonal antibody also proves successful in extending FGF21 plasma half-life (84). A mutated FGF21 molecule is conjugated to the Fab region of a scaffold antibody, CVX-200, via one of the four native lysine residues (K56, K59, $\mathrm{K} 69$, or K122) or one of the three positions mutated to cysteine
(D79C, H125C, and A129C). One such conjugated molecule, CVX-343, which is the fusion of the FGF21-A129C mutant to the scaffold antibody retains in vitro activity while increasing half-life up to 70-fold compared with wild-type FGF21. In diet-induced obese mice, weekly doses of CVX-343 reduce body weight, blood glucose, and lipid levels. In $o b / o b$ and $d b / d b$ mice, CVX-343 increases glucose tolerance, pancreatic beta-cell mass and proliferation, providing evidence of another half-life extended FGF21 molecule with improved preclinical pharmacokinetics while preserving full therapeutic functionality.

\section{Other FGF-Based Analogs}

Several other FGF molecules show similar effects on metabolism to FGF21 $(32,85)$. In addition, advances in understanding FGF/ receptor interactions/functions offer alternative approaches to engineer FGF21-like or mimetic molecules. So far, FGF19, FGF23, FGF1, and FGF2 have been explored for this concept.

The most advanced analog is based on FGF19. FGF21 and FGF19 share an extensive receptor binding profile and pharmacological effects [reviewed in Ref. $(32,86)]$. Both bind $\beta$-Klotho, and both activate $\beta$-Klotho complexed with FGFR1c, $2 c$, and 3c. Both FGF19 and FGF21 display a similar metabolic profile, such as lowering serum glucose, TG and cholesterol levels, as well as improving insulin sensitivity and reducing bodyweight in multiple disease models, suggesting that FGF19 could be an alternative to FGF21 for therapeutic development. However, the key concern for FGF19 is that in addition to FGFR1c, 2c, and 3c, FGF19 also regulates bile acid homeostasis and induces hepatocyte proliferation and HCC via activation of FGFR4 (51, 87-89). Therefore, selective removal of mitogenic activity is a strategy for FGF19 development. FGF19 variants devoid of the undesirable proliferative activities have been identified $(88,90-92)$ and one variant has been tested in humans (92), the efficacy and long-term safety profiles in humans remain to be established.

A similar strategy also proved successful for FGF1. FGF1, considered a prototypic FGF molecule discovered in the early 1970s, has also been shown recently to play a role in adaptive adipose remodeling and metabolism $(85,93)$. Similar to FGF19, the mitogenic and metabolic activities of FGF1 are separable. A variant of FGF1, devoid of mitogenic activity, improves glucose metabolism and insulin sensitivity in a rodent model, demonstrating a potential utility of FGF1 in treating diabetes in humans (85).

Structural and functional studies of various FGF molecules suggest another interesting approach where the core FGF sequence can be considered as a protein scaffold, and sequences outside the core can be considered as appendages enabling a specific biological activity through specific interactions with FGFRs, co-receptors, and/or heparin (90). This opens the possibility to explore the entire FGF family for designing the best candidate for development (90). Two successful examples are reported, one with endocrine factor, FGF23 (94), the other with a paracrine factor, FGF2 (95). In the case of FGF23, since it also activates FGFR1c, 2c, and 3c (94), but differs from FGF21 in co-receptor utilization $(6,96,97)$, the replacement of the $\alpha$-Klotho interacting FGF23 C-terminal domain with the $\beta$-Klotho interacting FGF21 C-terminal domain converts FGF23 into an FGF21-like 
molecule (94). In the case of FGF2, in addition to adding the $\beta$-Klotho interacting C-terminal region of FGF21 (P168-S209) to the FGF2 framework from M1 to M151, mutations in the HS-binding site (K128D/R129Q/K134V) are also needed to reduce heparin binding. The resulting molecule, FGF2 $2^{\Delta \mathrm{HBScore}_{-}}$ FGF21 $1^{\mathrm{C} \text {-tail }}$, loses heparin binding and HS-dependent activation of FGFR1c, but gains the ability to function like FGF21 to regulate metabolism (95).

\section{Non-FGF-Based Analogs}

While significant improvements have been made to FGF21 and other FGF-based FGF21 analogs, additional challenges may need to be addressed as the molecules progress through development. For example, potential induction of anti-drug antibodies that neutralize endogenous ligand function may pose risk in the clinic. Therefore, protein scaffolds or modalities that have more optimal drug-like properties, but do not have sequence homology to endogenous ligands, may circumvent challenges associated with the use of endogenous ligands themselves. Since FGF21's pharmacological function is mainly mediated through FGFR1c/ $\beta$-Klotho activation [reviewed in Ref. (32)], several innovative approaches using monoclonal antibodies (mAbs) and other stable scaffolds to target components of the receptor complex have been reported.

A subset of mAbs, identified through phage display screening that selectively bind both FGFR1 isotypes, are found to be agonistic and able to activate receptor signaling $(98,99)$. In multiple diabetic animal models, the injection of these FGFR1 agonistic antibodies induce acute and sustained serum glucose lowering, decrease serum insulin levels and bodyweight, and improve lipid profiles and hepatosteatosis. In fat tissue, FGF21 and anti-FGFR1 antibodies induce CREB phosphorylation and increase expression of PGC- $1 \alpha$, PGC- $1 \beta$, UCP- 1 and the downstream genes associated with oxidative metabolism. Overall, the effects of these agonist antibodies mimic FGF21 actions. Since these antibodies do not depend on $\beta$-Klotho to signal, the nontissue-specific activation of FGFR1 also induces undesirable side effects. For example, these antibodies induce FGF23 production and hypophosphatemia owing to their actions in bone and kidney, and potential ability to induce proliferation may be another concern $(98,100)$.

An antibody, mimAb1 identified through immunization of XenoMouse, specifically activates FGFR1c and is completely $\beta$-Klotho dependent (49). MimAb1 displays similar potency and efficacy in inducing ERK phosphorylation in vitro when compared with recombinant FGF21. In obese cynomolgus monkeys, mimAb1 injections result in reductions in bodyweight, plasma insulin and TG, and improvement in insulin sensitivity similar to Fc-FGF21, but with significantly extended duration of effect (49).

FGFR1/ $\beta$-Klotho specificity and $\beta$-Klotho dependency is also achieved through another approach, the generation of a bispecific molecule where one arm binds $\beta$-Klotho while the other binds FGFR1. This concept was first demonstrated using the Avimer ${ }^{\mathrm{TM}}$ scaffold. A-domain library is screened for Avimer ${ }^{\mathrm{TM}}$ polypeptides that bind FGFR1 or $\beta$-Klotho (101). The individual binders are then assembled into a single polypeptide, generating a bispecific molecule that binds to $\beta$-Klotho and FGFR1c simultaneously. One such bispecific avimer, C3201, is highly potent in FGF21-sensitive cell-based assays, activates FGFR1c signaling with efficacy similar to FGF2 1 and depends on $\beta$-Klotho. To extend its serum half-life, C3201 is fused to human serum albumin (HSA), and the resulting fusion molecule, C3201-HSA, exhibits a half-life sufficient for once-weekly dosing. When tested in male obese cynomolgus monkeys, animals treated with C3201-HSA show improved metabolic parameters with reduced bodyweight, insulin, and TG levels similar to FGF21 (101). Therefore, these data demonstrate the concept that a bispecific molecule, generated by fusing a FGFR1 binder and a $\beta$-Klotho binder together, can activate appropriate receptor signaling and mimic the activity of FGF21 in vitro and in vivo. Generation of such a bispecific molecule is not restricted to an Avimer scaffold, other scaffolds can also be used. A variation of this approach using a bispecific antibody has also been shown to be successful. FGFR1 binders and $\beta$-Klotho binders, obtained through phage display and immunization, respectively, are assembled using the knob and hole method (102). The resulting bispecific molecules resemble a normal antibody conformation except with the two arms capable of binding FGFR1 and $\beta$-Klotho separately. Similar to bispecific Avimers, these bispecific antibodies also display activities similar to FGF21, stimulate thermogenic activity in BAT, induce WAT browning, and ameliorate obesity, insulin resistance, and associated metabolic defects. Unlike the antibodies activate FGFR1 independent of $\beta$-Klotho, the bispecific antibodies do not alter serum FGF23 and phosphorus levels (98, $100,102)$, supporting the notion that increase target specificity through $\beta$-Klotho dependency reduces undesirable side effects of FGFR activation.

\section{SUMMARY}

An FGF21 therapeutic represents an attractive opportunity for novel drug development treating metabolic disorders. Many of its potent activities in improving glucose metabolism, lipid metabolism, inducing energy expenditure and reducing bodyweight, demonstrated in many rodent and non-human primate models, are translated to humans.

\section{TABLE 1 | Selected list of FGF21 analogs.}

\begin{tabular}{llc}
\hline Target & Compound (source) & Reference \\
\hline FGF21 analogs & LY2405319 (Eli Lilly) & $(70)$ \\
& SUMO-FGF21 (NAU) & $(72)$ \\
& FGF21/19 chimera (NYU) & $(77)$ \\
& FGF21(1-171)-WD22 (Amgen) & $(78)$ \\
FGF21 long-acting & PEG-FGF21 (WMC) & $(79)$ \\
analogs & PEG-FGF21 (Amgen) & $(80)$ \\
& ARX-618 (Ambrx/BMS) & $(81,109)$ \\
& FC-FGF21 (Amgen) & $(76)$ \\
Other FGF-based & CVX-343 (Pfizer) & $(88,90-92)$ \\
analogs & FGF19 variants (Amgen, & $(94)$ \\
& Genentech, NGM) & $(85)$ \\
& FGF23-21 (Amgen) & $(95)$ \\
Non-FGF-based & rFGF1 & $(9 \mathrm{NT}$ (Salk/NYU) \\
analogs & FGF2 ${ }^{\Delta H B S c o r e-F G F 21 ~}{ }^{\text {-tail }}$ (NYU) & $(49)$ \\
& R1Mab (Genentech) & $(101)$ \\
& mimAb1 (Amgen) & $(102)$
\end{tabular}


Various approaches successfully improve FGF21 stability, reduce aggregation, improve affinity toward receptor, and improve its manufacturability and productivity (Table 1). Additionally, FGF21-mimetic molecules utilizing completely distinct protein modalities, with no similarities to endogenous ligand, such as agonistic antibodies and bispecific Avimers, open new opportunities to identify best-in-class therapeutics for this pathway (Table 1). However, significant challenges also exist. Although initial clinical data provide encouraging signs of efficacy in humans, it is unclear if FGF21 could provide clinically meaningful improvements in hyperglycemia or more robust and durable responses in other metabolic parameters under chronic treatment conditions. In addition, studies in

\section{REFERENCES}

1. Itoh N, Ornitz DM. Fibroblast growth factors: from molecular evolution to roles in development, metabolism and disease. J Biochem (2011) 149:121-30. doi:10.1093/jb/mvq121

2. Kelleher FC, O'Sullivan H, Smyth E, McDermott R, Viterbo A. Fibroblast growth factor receptors, developmental corruption and malignant disease. Carcinogenesis (2013) 34:2198-205. doi:10.1093/carcin/bgt254

3. Itoh N, Ornitz DM. Evolution of the Fgf and Fgfr gene families. Trends Genet (2004) 20:563-9. doi:10.1016/j.tig.2004.08.007

4. Nishimura T, Nakatake Y, Konishi M, Itoh N. Identification of a novel FGF, FGF-21, preferentially expressed in the liver. Biochim Biophys Acta (2000) 1492:203-6. doi:10.1016/S0167-4781(00)00067-1

5. Inagaki T, Dutchak P, Zhao G, Ding X, Gautron L, Parameswara V, et al. Endocrine regulation of the fasting response by PPARalpha-mediated induction of fibroblast growth factor 21. Cell Metab (2007) 5:415-25. doi:10.1016/j. cmet.2007.05.003

6. Ogawa Y, Kurosu H, Yamamoto M, Nandi A, Rosenblatt KP, Goetz R, et al. BetaKlotho is required for metabolic activity of fibroblast growth factor 21. Proc Natl Acad Sci U S A (2007) 104:7432-7. doi:10.1073/ pnas.0701600104

7. Kharitonenkov A, Dunbar JD, Bina HA, Bright S, Moyers JS, Zhang C, et al. FGF-21/FGF-21 receptor interaction and activation is determined by betaKlotho. J Cell Physiol (2008) 215:1-7. doi:10.1002/jcp.21357

8. Suzuki M, Uehara Y, Motomura-Matsuzaka K, Oki J, Koyama Y, Kimura M, et al. BetaKlotho is required for fibroblast growth factor (FGF) 21 signaling through FGF receptor (FGFR) 1c and FGFR3c. Mol Endocrinol (2008) 22:1006-14. doi:10.1210/me.2007-0313

9. Itoh N. Hormone-like (endocrine) Fgfs: their evolutionary history and roles in development, metabolism, and disease. Cell Tissue Res (2010) 342:1-11. doi:10.1007/s00441-010-1024-2

10. Long YC, Kharitonenkov A. Hormone-like fibroblast growth factors and metabolic regulation. Biochim Biophys Acta (2011) 1812:791-5. doi:10.1016/j. bbadis.2011.04.002

11. Badman MK, Koester A, Flier JS, Kharitonenkov A, Maratos-Flier E. Fibroblast growth factor 21-deficient mice demonstrate impaired adaptation to ketosis. Endocrinology (2009) 150:4931-40. doi:10.1210/en.2009-0532

12. Planavila A, Redondo I, Hondares E, Vinciguerra M, Munts C, Iglesias R, et al. Fibroblast growth factor 21 protects against cardiac hypertrophy in mice. Nat Commun (2013) 4:2019. doi:10.1038/ncomms3019

13. Mraz M, Bartlova M, Lacinova Z, Michalsky D, Kasalicky M, Haluzikova D, et al. Serum concentrations and tissue expression of a novel endocrine regulator fibroblast growth factor-21 in patients with type 2 diabetes and obesity. Clin Endocrinol (2009) 71:369-75. doi:10.1111/j.1365-2265.2008.03502.x

14. Zhang X, Yeung DC, Karpisek M, Stejskal D, Zhou ZG, Liu F, et al. Serum FGF21 levels are increased in obesity and are independently associated with the metabolic syndrome in humans. Diabetes (2008) 57:1246-53. doi: $10.2337 / \mathrm{db} 07-1476$

15. Chavez AO, Molina-Carrion M, Abdul-Ghani MA, Folli F, Defronzo RA, Tripathy D. Circulating fibroblast growth factor-21 is elevated in impaired rodents with FGF21 reveal several potential areas of side-effect concerns that need monitoring, such as potential interactions with the growth hormone axis $(103,104)$, decreases in bone mineral density (105), increases in plasma corticosterone levels (106), cross-talk with the PPAR $\gamma$ axis (107), and female infertility (108). The human relevance of these rodent findings, as well as the potential differences in side-effect profiles among the different therapeutic approaches, will need to be evaluated in the future.

\section{ACKNOWLEDGMENTS}

We thank Simon Jackson for editing this manuscript.

glucose tolerance and type 2 diabetes and correlates with muscle and hepatic insulin resistance. Diabetes Care (2009) 32:1542-6. doi:10.2337/dc09-0684

16. Xiao Y, Xu A, Law LS, Chen C, Li H, Li X, et al. Distinct changes in serum fibroblast growth factor 21 levels in different subtypes of diabetes. J Clin Endocrinol Metab (2012) 97:E54-8. doi:10.1210/jc.2011-1930

17. Li H, Bao Y, Xu A, Pan X, Lu J, Wu H, et al. Serum fibroblast growth factor 21 is associated with adverse lipid profiles and gamma-glutamyltransferase but not insulin sensitivity in Chinese subjects. J Clin Endocrinol Metab (2009) 94:2151-6. doi:10.1210/jc.2008-2331

18. Yilmaz Y, Eren F, Yonal O, Kurt R, Aktas B, Celikel CA, et al. Increased serum FGF21 levels in patients with nonalcoholic fatty liver disease. Eur J Clin Invest (2010) 40:887-92. doi:10.1111/j.1365-2362.2010.02338.x

19. Li H, Fang Q, Gao F, Fan J, Zhou J, Wang X, et al. Fibroblast growth factor 21 levels are increased in nonalcoholic fatty liver disease patients and are correlated with hepatic triglyceride. J Hepatol (2010) 53:934-40. doi:10.1016/j. jhep.2010.05.018

20. Lin Z, Wu Z, Yin X, Liu Y, Yan X, Lin S, et al. Serum levels of FGF-21 are increased in coronary heart disease patients and are independently associated with adverse lipid profile. PLoS One (2010) 5:e15534. doi:10.1371/ journal.pone.0015534

21. Shen Y, Ma X, Zhou J, Pan X, Hao Y, Zhou M, et al. Additive relationship between serum fibroblast growth factor 21 level and coronary artery disease. Cardiovasc Diabetol (2013) 12:124. doi:10.1186/1475-2840-12-124

22. Chow WS, Xu A, Woo YC, Tso AW, Cheung SC, Fong CH, et al. Serum fibroblast growth factor-21 levels are associated with carotid atherosclerosis independent of established cardiovascular risk factors. Arterioscler Thromb Vasc Biol (2013) 33:2454-9. doi:10.1161/ATVBAHA.113.301599

23. Hindricks J, Ebert T, Bachmann A, Kralisch S, Lossner U, Kratzsch $J$, et al. Serum levels of fibroblast growth factor-21 are increased in chronic and acute renal dysfunction. Clin Endocrinol (2014) 80:918-24. doi: $10.1111 /$ cen. 12380

24. Lin Z, Zhou Z, Liu Y, Gong Q, Yan X, Xiao J, et al. Circulating FGF21 levels are progressively increased from the early to end stages of chronic kidney diseases and are associated with renal function in Chinese. PLoS One (2011) 6:e18398. doi:10.1371/journal.pone.0018398

25. Lee P, Brychta RJ, Linderman J, Smith S, Chen KY, Celi FS. Mild cold exposure modulates fibroblast growth factor 21 (FGF21) diurnal rhythm in humans: relationship between FGF21 levels, lipolysis, and cold-induced thermogenesis. J Clin Endocrinol Metab (2013) 98:E98-102. doi:10.1210/jc.2012-3107

26. Hanssen MJ, Broeders E, Samms RJ, Vosselman MJ, van der Lans AA, Cheng CC, et al. Serum FGF21 levels are associated with brown adipose tissue activity in humans. Sci Rep (2015) 5:10275. doi:10.1038/srep 10275

27. Kliewer SA, Mangelsdorf DJ. Fibroblast growth factor 21: from pharmacology to physiology. Am J Clin Nutr (2010) 91:254S-7S. doi:10.3945/ ajcn.2009.28449B

28. Kharitonenkov A, Larsen P. FGF21 reloaded: challenges of a rapidly growing field. Trends Endocrinol Metab (2011) 22:81-6. doi:10.1016/j.tem.2010.11.003

29. Potthoff MJ, Kliewer SA, Mangelsdorf DJ. Endocrine fibroblast growth factors 15/19 and 21: from feast to famine. Genes Dev (2012) 26:312-24. doi:10.1101/gad.184788.111 
30. Angelin B, Larsson TE, Rudling M. Circulating fibroblast growth factors as metabolic regulators - a critical appraisal. Cell Metab (2012) 16:693-705. doi:10.1016/j.cmet.2012.11.001

31. Kharitonenkov A, Adams AC. Inventing new medicines: the FGF21 story. Mol Metab (2014) 3:221-9. doi:10.1016/j.molmet.2013.12.003

32. Zhang J, Li Y. Fibroblast growth factor 21, the endocrine FGF pathway and novel treatments for metabolic syndrome. Drug Discov Today (2014) 19:579-89. doi:10.1016/j.drudis.2013.10.021

33. Gimeno RE, Moller DE. FGF21-based pharmacotherapy - potential utility for metabolic disorders. Trends Endocrinol Metab (2014) 25:303-11. doi:10.1016/j.tem.2014.03.001

34. Owen BM, Mangelsdorf DJ, Kliewer SA. Tissue-specific actions of the metabolic hormones FGF15/19 and FGF21. Trends Endocrinol Metab (2015) 26:22-9. doi:10.1016/j.tem.2014.10.002

35. Kharitonenkov A, Shiyanova TL, Koester A, Ford AM, Micanovic R, Galbreath EJ, et al. FGF-21 as a novel metabolic regulator. J Clin Invest (2005) 115:1627-35. doi:10.1172/JCI23606

36. Ding X, Boney-Montoya J, Owen BM, Bookout AL, Coate KC, Mangelsdorf DJ, et al. BetaKlotho is required for fibroblast growth factor 21 effects on growth and metabolism. Cell Metab (2012) 16:387-93. doi:10.1016/j. cmet.2012.08.002

37. Zhang Y, Xie Y, Berglund ED, Coate KC, He TT, Katafuchi T, et al. The starvation hormone, fibroblast growth factor-21, extends lifespan in mice. Elife (2012) 1:e00065. doi:10.7554/eLife.00065

38. Coskun T, Bina HA, Schneider MA, Dunbar JD, Hu CC, Chen Y, et al. Fibroblast growth factor 21 corrects obesity in mice. Endocrinology (2008) 149:6018-27. doi:10.1210/en.2008-0816

39. Xu J, Lloyd DJ, Hale C, Stanislaus S, Chen M, Sivits G, et al. Fibroblast growth factor 21 reverses hepatic steatosis, increases energy expenditure, and improves insulin sensitivity in diet-induced obese mice. Diabetes (2009) 58:250-9. doi:10.2337/db08-0392

40. Berglund ED, Li CY, Bina HA, Lynes SE, Michael MD, Shanafelt AB, et al. Fibroblast growth factor 21 controls glycemia via regulation of hepatic glucose flux and insulin sensitivity. Endocrinology (2009) 150:4084-93. doi:10.1210/en.2009-0221

41. Xu J, Stanislaus S, Chinookoswong N, Lau YY, Hager T, Patel J, et al. Acute glucose-lowering and insulin-sensitizing action of FGF21 in insulin-resistant mouse models - association with liver and adipose tissue effects. Am J Physiol Endocrinol Metab (2009) 297:E1105-14. doi:10.1152/ ajpendo.00348.2009

42. Kharitonenkov A, Wroblewski VJ, Koester A, Chen YF, Clutinger CK, Tigno XT, et al. The metabolic state of diabetic monkeys is regulated by fibroblast growth factor-21. Endocrinology (2007) 148:774-81. doi:10.1210/ en.2006-1168

43. Arner P, Pettersson A, Mitchell PJ, Dunbar JD, Kharitonenkov A, Ryden M. FGF21 attenuates lipolysis in human adipocytes - a possible link to improved insulin sensitivity. FEBS Lett (2008) 582:1725-30. doi:10.1016/j. febslet.2008.04.038

44. Li X, Ge H, Weiszmann J, Hecht R, Li YS, Veniant MM, et al. Inhibition of lipolysis may contribute to the acute regulation of plasma FFA and glucose by FGF21 in ob/ob mice. FEBS Lett (2009) 583:3230-4. doi:10.1016/j. febslet.2009.09.012

45. Holland WL, Adams AC, Brozinick JT, Bui HH, Miyauchi Y, Kusminski CM, et al. An FGF21-adiponectin-ceramide axis controls energy expenditure and insulin action in mice. Cell Metab (2013) 17:790-7. doi:10.1016/j. cmet.2013.03.019

46. Lin Z, Tian H, Lam KS, Lin S, Hoo RC, Konishi M, et al. Adiponectin mediates the metabolic effects of FGF21 on glucose homeostasis and insulin sensitivity in mice. Cell Metab (2013) 17:779-89. doi:10.1016/j.cmet.2013.04.005

47. Shimomura I, Hammer RE, Richardson JA, Ikemoto S, Bashmakov Y, Goldstein JL, et al. Insulin resistance and diabetes mellitus in transgenic mice expressing nuclear SREBP-1c in adipose tissue: model for congenital generalized lipodystrophy. Genes Dev (1998) 12:3182-94. doi:10.1101/ gad.12.20.3182

48. Veniant MM, Hale C, Helmering J, Chen MM, Stanislaus S, Busby J, et al. FGF21 promotes metabolic homeostasis via white adipose and leptin in mice. PLoS One (2012) 7:e40164. doi:10.1371/journal.pone.0040164

49. Foltz IN, Hu S, King C, Wu X, Yang C, Wang W, et al. Treating diabetes and obesity with an FGF21-mimetic antibody activating the betaKlotho/
FGFR1c receptor complex. Sci Transl Med (2012) 4:162ra153. doi:10.1126/ scitranslmed.3004690

50. Adams AC, Yang C, Coskun T, Cheng CC, Gimeno RE, Luo Y, et al. The breadth of FGF21's metabolic actions are governed by FGFR1 in adipose tissue. Mol Metab (2013) 2:31. doi:10.1016/j.molmet.2012.08.007

51. Kurosu H, Choi M, Ogawa Y, Dickson AS, Goetz R, Eliseenkova AV, et al. Tissue-specific expression of betaKlotho and fibroblast growth factor (FGF) receptor isoforms determines metabolic activity of FGF19 and FGF21. J Biol Chem (2007) 282:26687-95. doi:10.1074/jbc.M704165200

52. Fisher FM, Estall JL, Adams AC, Antonellis PJ, Bina HA, Flier JS, et al. Integrated regulation of hepatic metabolism by fibroblast growth factor 21 (FGF21) in vivo. Endocrinology (2011) 152:2996-3004. doi:10.1210/ en.2011-0281

53. Fisher FM, Kleiner S, Douris N, Fox EC, Mepani RJ, Verdeguer F, et al. FGF21 regulates PGC-1alpha and browning of white adipose tissues in adaptive thermogenesis. Genes Dev (2012) 26:271-81. doi:10.1101/gad.177857.111

54. Chartoumpekis DV, Habeos IG, Ziros PG, Psyrogiannis AI, Kyriazopoulou VE, Papavassiliou AG. Brown adipose tissue responds to cold and adrenergic stimulation by induction of FGF21. Mol Med (2011) 17:736-40. doi:10.2119/ molmed.2011.00075

55. Hondares E, Iglesias R, Giralt A, Gonzalez FJ, Giralt M, Mampel T, et al. Thermogenic activation induces FGF21 expression and release in brown adipose tissue. J Biol Chem (2011) 286:12983-90. doi:10.1074/jbc.M110.215889

56. Samms RJ, Smith DP, Cheng CC, Antonellis PP, Perfield JW II, Kharitonenkov A, et al. Discrete aspects of FGF21 in vivo pharmacology do not require UCP1. Cell Rep (2015) 11:991-9. doi:10.1016/j.celrep.2015.04.046

57. Veniant MM, Sivits G, Helmering J, Komorowski R, Lee J, Fan W, et al. Pharmacologic effects of FGF21 are independent of the "browning" of white adipose tissue. Cell Metab (2015) 21:731-8. doi:10.1016/j.cmet.2015.04.019

58. Badman MK, Pissios P, Kennedy AR, Koukos G, Flier JS, Maratos-Flier E. Hepatic fibroblast growth factor 21 is regulated by PPARalpha and is a key mediator of hepatic lipid metabolism in ketotic states. Cell Metab (2007) 5:426-37. doi:10.1016/j.cmet.2007.05.002

59. Lundasen T, Hunt MC, Nilsson LM, Sanyal S, Angelin B, Alexson SE, et al. PPARalpha is a key regulator of hepatic FGF21. Biochem Biophys Res Commun (2007) 360:437-40. doi:10.1016/j.bbrc.2007.06.068

60. Liu WY, Huang S, Shi KQ, Zhao CC, Chen LL, Braddock M, et al. The role of fibroblast growth factor 21 in the pathogenesis of liver disease: a novel predictor and therapeutic target. Expert Opin Ther Targets (2014) 18:1305-13. d oi: $10.1517 / 14728222.2014 .944898$

61. Fisher FM, Chui PC, Nasser IA, Popov Y, Cunniff JC, Lundasen T, et al. Fibroblast growth factor 21 limits lipotoxicity by promoting hepatic fatty acid activation in mice on methionine and choline-deficient diets. Gastroenterology (2014) 147:1073-83.e6. doi:10.1053/j.gastro.2014.07.044

62. Jian WX, Peng WH, Jin J, Chen XR, Fang WJ, Wang WX, et al. Association between serum fibroblast growth factor 21 and diabetic nephropathy. Metabolism (2012) 61:853-9. doi:10.1016/j.metabol.2011.10.012

63. Kim HW, Lee JE, Cha JJ, Hyun YY, Kim JE, Lee MH, et al. Fibroblast growth factor 21 improves insulin resistance and ameliorates renal injury in $\mathrm{db} / \mathrm{db}$ mice. Endocrinology (2013) 154:3366-76. doi:10.1210/en.2012-2276

64. Fisher FM, Chui PC, Antonellis PJ, Bina HA, Kharitonenkov A, Flier JS, et al. Obesity is a fibroblast growth factor 21 (FGF21)-resistant state. Diabetes (2010) 59:2781-9. doi:10.2337/db10-0193

65. An SY, Lee MS, Yi SA, Ha ES, Han SJ, Kim HJ, et al. Serum fibroblast growth factor 21 was elevated in subjects with type 2 diabetes mellitus and was associated with the presence of carotid artery plaques. Diabetes Res Clin Pract (2012) 96:196-203. doi:10.1016/j.diabres.2012.01.004

66. Xiao Y, Liu L, Xu A, Zhou P, Long Z, Tu Y, et al. Serum fibroblast growth factor 21 levels are related to subclinical atherosclerosis in patients with type 2 diabetes. Cardiovasc Diabetol (2015) 14:72. doi:10.1186/s12933-015-0229-9

67. Planavila A, Redondo-Angulo I, Ribas F, Garrabou G, Casademont J, Giralt $\mathrm{M}$, et al. Fibroblast growth factor 21 protects the heart from oxidative stress. Cardiovasc Res (2015) 106:19-31. doi:10.1093/cvr/cvu263

68. Brahma MK, Adam RC, Pollak NM, Jaeger D, Zierler KA, Pocher N, et al. Fibroblast growth factor 21 is induced upon cardiac stress and alters cardiac lipid homeostasis. J Lipid Res (2014) 55:2229-41. doi:10.1194/ jlr.M044784

69. So WY, Cheng Q, Chen L, Evans-Molina C, Xu A, Lam KS, et al. High glucose represses beta-klotho expression and impairs fibroblast growth factor 21 
action in mouse pancreatic islets: involvement of peroxisome proliferator-activated receptor gamma signaling. Diabetes (2013) 62:3751-9. doi:10.2337/ db13-0645

70. Gaich G, Chien JY, Fu H, Glass LC, Deeg MA, Holland WL, et al. The effects of LY2405319, an FGF21 analog, in obese human subjects with type 2 diabetes. Cell Metab (2013) 18:333-40. doi:10.1016/j.cmet.2013.08.005

71. Adams AC, Halstead CA, Hansen BC, Irizarry AR, Martin JA, Myers SR, et al. LY2405319, an engineered FGF21 variant, improves the metabolic status of diabetic monkeys. PLoS One (2013) 8:e65763. doi:10.1371/journal. pone. 0065763

72. Ye XL, Gao HS, Wang WF, Ren GP, Liu MY, He K, et al. [Optimization and characterization of a novel FGF21 mutant]. Yao Xue Xue Bao (2012) 47:897-903.

73. Wu X, Lemon B, Li X, Gupte J, Weiszmann J, Stevens J, et al. C-terminal tail of FGF19 determines its specificity toward klotho co-receptors. J Biol Chem (2008) 283:33304-9. doi:10.1074/jbc.M803319200

74. Yie J, Hecht R, Patel J, Stevens J, Wang W, Hawkins N, et al. FGF21 N- and C-termini play different roles in receptor interaction and activation. FEBS Lett (2009) 583:19-24. doi:10.1016/j.febslet.2008.11.023

75. Micanovic R, Raches DW, Dunbar JD, Driver DA, Bina HA, Dickinson CD, et al. Different roles of N- and C- termini in the functional activity of FGF21. J Cell Physiol (2009) 219:227-34. doi:10.1002/jcp.21675

76. Hecht R, Li YS, Sun J, Belouski E, Hall M, Hager T, et al. Rationale-based engineering of a potent long-acting FGF21 analog for the treatment of type 2 diabetes. PLoS One (2012) 7:e49345. doi:10.1371/journal.pone.0049345

77. Goetz R, Ohnishi M, Ding X, Kurosu H, Wang L, Akiyoshi J, et al. Klotho coreceptors inhibit signaling by paracrine fibroblast growth factor 8 subfamily ligands. Mol Cell Biol (2012) 32:1944-54. doi:10.1128/MCB.06603-11

78. Smith R, Duguay A, Weiszmann J, Stanislaus S, Belouski E, Cai L, et al. A novel approach to improve the function of FGF21. BioDrugs (2013) 27:159-66. doi:10.1007/s40259-013-0013-x

79. Huang Z, Wang H, Lu M, Sun C, Wu X, Tan Y, et al. A better anti-diabetic recombinant human fibroblast growth factor 21 (rhFGF21) modified with polyethylene glycol. PLoS One (2011) 6:e20669. doi:10.1371/journal. pone.0020669

80. Xu J, Bussiere J, Yie J, Sickmier A, An P, Belouski E, et al. Polyethylene glycol modified FGF21 engineered to maximize potency and minimize vacuole formation. Bioconjug Chem (2013) 24:915-25. doi:10.1021/bc300603k

81. Mu J, Pinkstaff J, Li Z, Skidmore L, Li N, Myler H, et al. FGF21 analogs of sustained action enabled by orthogonal biosynthesis demonstrate enhanced antidiabetic pharmacology in rodents. Diabetes (2012) 61:505-12. doi:10.2337/db11-0838

82. Hager T, Spahr C, Xu J, Salimi-Moosavi H, Hall M. Differential enzymelinked immunosorbent assay and ligand-binding mass spectrometry for analysis of biotransformation of protein therapeutics: application to various FGF21 modalities. Anal Chem (2013) 85:2731-8. doi:10.1021/ac303203y

83. Veniant MM, Komorowski R, Chen P, Stanislaus S, Winters K, Hager T, et al. Long-acting FGF21 has enhanced efficacy in diet-induced obese mice and in obese rhesus monkeys. Endocrinology (2012) 153:4192-203. doi:10.1210/ en.2012-1211

84. Huang J, Ishino T, Chen G, Rolzin P, Osothprarop TF, Retting K, et al. Development of a novel long-acting antidiabetic FGF21 mimetic by targeted conjugation to a scaffold antibody. J Pharmacol Exp Ther (2013) 346:270-80. doi:10.1124/jpet.113.204420

85. Suh JM, Jonker JW, Ahmadian M, Goetz R, Lackey D, Osborn O, et al. Endocrinization of FGF1 produces a neomorphic and potent insulin sensitizer. Nature (2014) 513:436-9. doi:10.1038/nature13540

86. Wu X, Li Y. Understanding the structure-function relationship between FGF19 and its mitogenic and metabolic activities. Adv Exp Med Biol (2012) 728:195-213. doi:10.1007/978-1-4614-0887-1_13

87. Wu X, Ge H, Lemon B, Vonderfecht S, Weiszmann J, Hecht R, et al. FGF19induced hepatocyte proliferation is mediated through FGFR4 activation. $J$ Biol Chem (2010) 285:5165-70. doi:10.1074/jbc.M109.068783

88. Wu AL, Coulter S, Liddle C, Wong A, Eastham-Anderson J, French DM, et al. FGF19 regulates cell proliferation, glucose and bile acid metabolism via FGFR4-dependent and independent pathways. PLoS One (2011) 6:e17868. doi:10.1371/journal.pone.0017868
89. French DM, Lin BC, Wang M, Adams C, Shek T, Hotzel K, et al. Targeting FGFR4 inhibits hepatocellular carcinoma in preclinical mouse models. PLoS One (2012) 7:e36713. doi:10.1371/journal.pone.0036713

90. Wu X, Ge H, Lemon B, Vonderfecht S, Baribault H, Weiszmann J, et al. Separating mitogenic and metabolic activities of fibroblast growth factor 19 (FGF19). Proc Natl Acad Sci U S A (2010) 107:14158-63. doi:10.1073/ pnas. 1009427107

91. Ge H, Baribault H, Vonderfecht S, Lemon B, Weiszmann J, Gardner J, et al. Characterization of a FGF19 variant with altered receptor specificity revealed a central role for FGFR1c in the regulation of glucose metabolism. PLoS One (2012) 7:e33603. doi:10.1371/journal.pone.0033603

92. Luo J, Ko B, Elliott M, Zhou M, Lindhout DA, Phung V, et al. A nontumorigenic variant of FGF19 treats cholestatic liver diseases. Sci Transl Med (2014) 6:247ra100. doi:10.1126/scitranslmed.3009098

93. Jonker JW, Suh JM, Atkins AR, Ahmadian M, Li P, Whyte J, et al. A PPARgamma-FGF1 axis is required for adaptive adipose remodelling and metabolic homeostasis. Nature (2012) 485:391-4. doi:10.1038/ nature10998

94. Wu X, Weiszmann J, Ge H, Baribault H, Stevens J, Hawkins N, et al. A unique FGF23 with the ability to activate FGFR signaling through both alphaKlotho and betaKlotho. J Mol Biol (2012) 418:82-9. doi:10.1016/j.jmb.2012.02.027

95. Goetz R, Ohnishi M, Kir S, Kurosu H, Wang L, Pastor J, et al. Conversion of a paracrine fibroblast growth factor into an endocrine fibroblast growth factor. J Biol Chem (2012) 287:29134-46. doi:10.1074/jbc.M112.342980

96. Urakawa I, Yamazaki Y, Shimada T, Iijima K, Hasegawa H, Okawa K, et al. Klotho converts canonical FGF receptor into a specific receptor for FGF23. Nature (2006) 444:770-4. doi:10.1038/nature05315

97. Kurosu H, Ogawa Y, Miyoshi M, Yamamoto M, Nandi A, Rosenblatt KP, et al. Regulation of fibroblast growth factor-23 signaling by klotho. J Biol Chem (2006) 281:6120-3. doi:10.1074/jbc.C500457200

98. Wu AL, Kolumam G, Stawicki S, Chen Y, Li J, Zavala-Solorio J, et al. Amelioration of type 2 diabetes by antibody-mediated activation of fibroblast growth factor receptor 1. Sci Transl Med (2011) 3:113ra126. doi:10.1126/ scitranslmed.3002669

99. Lelliott CJ, Ahnmark A, Admyre T, Ahlstedt I, Irving L, Keyes F, et al. Monoclonal antibody targeting of fibroblast growth factor receptor $1 \mathrm{c}$ ameliorates obesity and glucose intolerance via central mechanisms. PLoS One (2014) 9:e112109. doi:10.1371/journal.pone.0112109

100. Wu AL, Feng B, Chen MZ, Kolumam G, Zavala-Solorio J, Wyatt SK, et al. Antibody-mediated activation of FGFR1 induces FGF23 production and hypophosphatemia. PLoS One (2013) 8:e57322. doi:10.1371/journal. pone.0057322

101. Smith R, Duguay A, Bakker A, Li P, Weiszmann J, Thomas MR, et al. FGF21 can be mimicked in vitro and in vivo by a novel anti-FGFR1c/betaklotho bispecific protein. PLoS One (2013) 8:e61432. doi:10.1371/journal. pone.0061432

102. Kolumam G, Chen MZ, Tong R, Zavala-Solorio J, Kates L, van Bruggen $\mathrm{N}$, et al. Sustained brown fat stimulation and insulin sensitization by a humanized bispecific antibody agonist for fibroblast growth factor receptor 1/ßKlotho complex. EBioMedicine (2015) 2:730-43. doi:10.1016/j. ebiom.2015.05.028

103. Inagaki T, Lin VY, Goetz R, Mohammadi M, Mangelsdorf DJ, Kliewer SA. Inhibition of growth hormone signaling by the fasting-induced hormone FGF21. Cell Metab (2008) 8:77-83. doi:10.1016/j.cmet.2008.05.006

104. Wu S, Levenson A, Kharitonenkov A, De Luca F. Fibroblast growth factor 21 (FGF21) inhibits chondrocyte function and growth hormone action directly at the growth plate. J Biol Chem (2012) 287:26060-7. doi:10.1074/ jbc.M112.343707

105. Wei W, Dutchak PA, Wang X, Ding X, Wang X, Bookout AL, et al. Fibroblast growth factor 21 promotes bone loss by potentiating the effects of peroxisome proliferator-activated receptor gamma. Proc Natl Acad Sci U S A (2012) 109:3143-8. doi:10.1073/pnas.1200797109

106. Bookout AL, de Groot MH, Owen BM, Lee S, Gautron L, Lawrence HL, et al. FGF21 regulates metabolism and circadian behavior by acting on the nervous system. Nat Med (2013) 19:1147-52. doi:10.1038/nm.3249

107. Dutchak PA, Katafuchi T, Bookout AL, Choi JH, Yu RT, Mangelsdorf DJ, et al. Fibroblast growth factor-21 regulates PPARgamma activity and 
the antidiabetic actions of thiazolidinediones. Cell (2012) 148:556-67. doi:10.1016/j.cell.2011.11.062

108. Owen BM, Bookout AL, Ding X, Lin VY, Atkin SD, Gautron L, et al. FGF21 contributes to neuroendocrine control of female reproduction. Nat Med (2013) 19:1153-6. doi:10.1038/nm.3250

109. Camacho RC, Zafian PT, Achanfuo-Yeboah J, Manibusan A, Berger JP. Pegylated Fgf21 rapidly normalizes insulin-stimulated glucose utilization in diet-induced insulin resistant mice. Eur J Pharmacol (2013) 715:41-5. doi:10.1016/j.ejphar.2013.06.023
Conflict of Interest Statement: Both authors are full-time employees of Amgen Inc.

Copyright (ङ 2015 Zhang and Li. This is an open-access article distributed under the terms of the Creative Commons Attribution License (CC BY). The use, distribution or reproduction in other forums is permitted, provided the original author(s) or licensor are credited and that the original publication in this journal is cited, in accordance with accepted academic practice. No use, distribution or reproduction is permitted which does not comply with these terms. 